\title{
AN EMBEDDING THEOREM WITH MODIFIED AND RELAXED CONDITIONS
}

\section{LÁSZLÓ LEINDLER}

Abstract. In this note we prove an embedding theorem on the interrelation between the class $W^{r} H_{\beta}^{\omega}$ and the class $H(\lambda, p, r, \omega)$, defined by strong means of Fourier series, continuing the recent investigations due to S. Tikhonov [5] and R. J. Le and S. P. Zhou [1].

Mathematics subject classification (2010): 42A20, 42A32.

Keywords and phrases: Fourier series, strong approximation, generalized monotone sequences.

\section{REFERENCES}

[1] R. J. LE AND S. P. ZHOU, A note on strong approximation of Fourier series and embedding theorems, Math. Ineq. and Appl., 11, 4 (2008), 749-756.

[2] L. LeIndLER, Some inequalities of Hardy-Littlewood type, Analysis Math., 20 (1994), 95-106.

[3] L. LeindleR, Two Hardy-Bennett-type theorems, Acta Math. Hungar., 85, 3 (1999), 265-276.

[4] L. LEINDLER, A new class of numerical sequences and its applications to sine and cosine series, Analysis Math., 28 (2002), 279-286.

[5] S. TIKHONOv, Strong approximation of Fourier series and embedding theorems, Analysis Math., 31 (2005), 183-194.

[6] S. P. Zhou, P. Zhou AND D. S. YU, Ultimate generalization of monotonicity for uniform convergence of trigonometric series, arXiv: math. CA/0611805 v1 November 27, 2006, preprint, it will appear in Science in China, Series A, in 2010. 